\title{
Silicon Granuloma
}

National Cancer Institute

\section{Source}

National Cancer Institute. Silicon Granuloma. NCI Thesaurus. Code C9248.

A granuloma that forms in response to silicone exposure. 